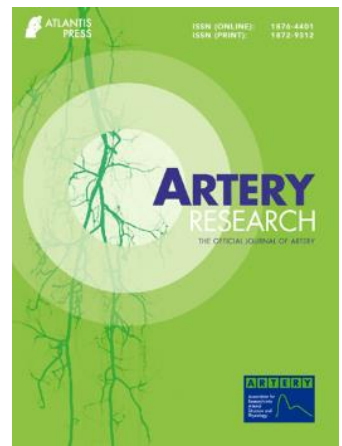

Artery Research

ISSN (Online): 1876-4401 ISSN (Print): 1872-9312

Journal Home Page: https://www.atlantis-press.com/journals/artres

\title{
Application of non-invasive central aortic pressure assessment in clinical trials: Clinical experience and value
}

Bryan Williams, Patrick Brunel, Peter S. Lacy, Fabio Baschiera, Dion H. Zappe, Kazuomi Kario, John Cockcroft

To cite this article: Bryan Williams, Patrick Brunel, Peter S. Lacy, Fabio Baschiera, Dion H. Zappe, Kazuomi Kario, John Cockcroft (2016) Application of non-invasive central aortic pressure assessment in clinical trials: Clinical experience and value, Artery Research 17:C, 1-15, DOI: https://doi.org/10.1016/j.artres.2016.10.154

To link to this article: https://doi.org/10.1016/j.artres.2016.10.154

Published online: 3 December 2019 


\title{
Review
}

\section{Application of non-invasive central aortic pressure assessment in clinical trials: Clinical experience and value}

\author{
Bryan Williams $^{\text {a,b,* }}$, Patrick Brunel ${ }^{c}$, Peter S. Lacy ${ }^{a, b}$, \\ Fabio Baschiera ${ }^{c}$, Dion H. Zappe ${ }^{d}$, Kazuomi Kario ${ }^{e}$, \\ John Cockcroft ${ }^{f}$
}

${ }^{a}$ Institute of Cardiovascular Science, University College London, London, W1T 7DN, UK

${ }^{\mathrm{b}}$ National Institute for Health Research, University College London Hospitals Biomedical Research

Centre, London, W1T 7DN, UK

' Novartis Pharma AG, CH-4002, Basel, Switzerland

d Novartis Pharmaceuticals Corporation, East Hanover, NJ, USA

e Jichi Medical School, Tochigi, 329-0498, Japan

${ }^{\mathrm{f}}$ Department of Cardiology, University of Cardiff, CF 14 4XN, Wales, UK

Received 21 March 2016; received in revised form 5 October 2016; accepted 19 October 2016 Available online 5 December 2016

\section{KEYWORDS \\ Arterial stiffness; \\ Applanation \\ tonometry; \\ Central aortic \\ pressure; \\ Clinical outcomes; \\ Hemodynamics; \\ Pulse waveform \\ analysis; \\ Wave reflection}

\begin{abstract}
Pressure measured with a cuff and sphygmomanometer in the brachial artery is accepted as an important predictor of future cardiovascular (CV) events. However, recent clinical evidence suggests that central aortic pressure (CAP) provides additional information for assessing CV risk than brachial blood pressure (BrBP). Central hemodynamics can now be noninvasively assessed with a number of devices, however, the methodology employed to measure CAP, in order to better identify the patients at higher CV risk in clinical practice, is still controversial. The purpose of this article is to review the technology behind the non-invasive measurement of CAP via the effects of different classes of antihypertensive drugs on CAP and the data supporting the predictive value of assessing CAP on clinical outcomes, and to foster the transfer of methodological knowledge from clinical trials into routine clinical practice.

(C) 2016 Association for Research into Arterial Structure and Physiology. Published by Elsevier B.V. All rights reserved.
\end{abstract}

\footnotetext{
* Corresponding author. Institute of Cardiovascular Science, University College London, London, W1T 7DN, UK. E-mail address: bryan.williams@ucl.ac.uk (B. Williams).
} 


\section{Introduction}

Brachial blood pressure (BrBP) is an accepted surrogate marker and major independent risk factor for cardiovascular (CV) disease and decreases in blood pressure have been demonstrated to correlate with reduced incidence of myocardial infarction and stroke. ${ }^{1}$ However, the BP profile varies along the arterial tree from its origin to the periphery with mean and diastolic BP being relatively constant while systolic BP is higher in the periphery than in the aorta and elastic central arteries. ${ }^{2}$ Thus, systolic BP (SBP) values are dependent on the site of measurement. Central aortic systolic pressure (CASP) appears to be a more relevant measurement than peripheral pressure, as the aortic pressure the target organ beds receives is proportional to the pressure developed by the left ventricle to propel blood against the arterial pressure. The arterial pressure waveform used to calculate CASP is composed of the forward pressure wave created by ventricular contraction and a reflected wave, originating from the primary wave hitting intersections between elastic and more muscular arteries: the overlap between the anterograde and retrograde reflected waves producing the amplification phenomenon of the arterial pressure wave observed in the aorta. ${ }^{2}$

$\mathrm{BrBP}$ is thus a composite measure of both the CAP and the degree of amplification of the central pressure. The relationship between CAP and BrBP is not fixed, as it depends on a number of factors including arterial wall distensibility and arterial pressure, and the ratio between the two BPs has been termed the amplification ratio. The relationship between $\mathrm{CAP}$ and $\mathrm{BrBP}$, specifically the respective pulse pressures, is also strongly dependent upon heart rate. In some hypertensive patients a reduced amplification ratio may be an indicator of the stiffness of the arterial tree. BrBP is usually higher than CAP due to pressure wave amplification. ${ }^{2}$ Systolic pressure amplification is the ratio between brachial and central SBP and pulse pressure amplification (PPA) is the ratio of brachial to central PP. In healthy individuals PPA is approximately 1.5 and varies from 1.7 at $<20$ years of age to 1.2 at $>80$ years of age. ${ }^{3}$ PPA is variable between subjects but relatively constant for a given individual reflecting the degree of stiffness of the large arteries and the magnitude of wave reflections. $^{4}$

A number of factors such as age, heart rate and height have differential effects on central and peripheral pressure. In addition, CV risk factors such as hypercholesterolemia, hypertension, smoking and metabolic syndromes, which accelerate aortic stiffening in the large arteries, may have greater effects on CAP. ${ }^{5}$ CAP increases with age in part because large arteries become stiffer with age, is reduced by low heart rate and shorter body height (reflecting reducing aortic length and volume), and is reduced with low diastolic pressure. Female gender on average is associated with a lower CAP in comparison with males, although PPA is generally lower in females indicative of a higher central relative to brachial pressure. , $^{6,7}$

CAP at the aortic root is regarded as an index of aortic stiffness and represents the true load imposed on heart, brain, kidney and large arteries. ${ }^{8-10}$ Recent studies have shown that CAP and CAPP are better predictors of CV events and mortality than BrBP. ${ }^{11,12}$ CAP has also demonstrated clinical value in predicting clinical outcomes in selected populations such as patients with end-stage renal disease (ESRD) and patients with coronary artery disease (CAD) undergoing percutaneous coronary intervention. ${ }^{8,9}$ CAP measurement is of clinical relevance since it predicts clinical outcomes in both general populations and in patients with $\mathrm{CV}$ risk factors. ${ }^{13}$ Previous studies have looked at the predictive power of central versus peripheral pressure measurements, ${ }^{8,12,14,15}$ and a meta-analysis by Vlachopoulos et al. ${ }^{11}$ has shown a trend for CAPP to be more predictive than BrPP $(p=0.057)$, while no difference for SBP was observed.

The 2003 ESC/ESH guidelines for the management of arterial hypertension recommend that the assessment of total CV risk includes an assessment of target organ damage. CAP is dependent on pulse wave velocity (PWV) and augmentation index (Alx) that are linked to the development of target organ damage in patients with hypertension. ${ }^{16}$ CAP varies between subjects, and antihypertensive agents (i.e. primarily beta-blockers and heart rate modulating agents) have shown differential effects on CAP despite similar effects on BrBP. ${ }^{17}$ A substantial overlap of central and brachial BP among categories of hypertension implies that based simply on the brachial cuff BP, but in reference to the effects of central aortic BP on end-organ damage, there are some individuals who should be treated and who are not and others who are on treatment and perhaps might not require $\mathrm{it}^{5,18}$ : the paradigm shift that was suggested in the BP Guide study. Measuring CAP in addition to $\mathrm{BrBP}$ in patients with $\mathrm{CV}$ risk may provide additional information and further characterize blood pressure patterns to improve treatment decisions. The BP GUIDE (value of central Blood Pressure for GUIDing managEment of hypertension) study showed that central BP guidance for hypertension management resulted in a significant reduction in the quantity of antihypertensive medication (across all drug classes) needed to achieve BP control. ${ }^{19}$ A recent critical analysis between brachial and central systolic pressure showed that their standard deviations were nearly identical. ${ }^{20}$ This is because the population variation caused by PPA is counterbalanced by the larger measurement and model errors embedded in central SBP. The practical implication is that in a comparative study, the sample size needs to be roughly the same whether brachial or central SBP is used as the primary dependent variable.

Until recently, CAP could only be assessed by invasive measurement. Since 2002, several non-invasive techniques, primarily applanation tonometry have been developed to estimate CAP. Cuff BrBP has been commonly used to calibrate peripheral pulse waveforms, the basis for all CAP estimation methods, obtained by tonometry. ${ }^{21}$ The widespread use of CAP measurement is hindered by the availability of diverse non-invasive devices and standardization of the method; furthermore, an evidence gap still exists on the predictive value of CAP in prospective studies. The aim of this review is to highlight the clinical relevance of CAP, which can be non-invasively measured in multicenter clinical trials, to assess the effects of antihypertensive treatments on CAP in comparison to BrBP and to better understand their respective predictive value for outcomes. 


\section{Non-invasive measurement of central aortic pressure}

To evaluate CAP, a variety of non-invasive devices have been developed and made available primarily to specialists and researchers. Techniques for measuring CAP, apart from direct intra-aortic CAP measurement by aortic catheterization, are dependent on the capture of an arterial waveform. There are two methods currently used to capture arterial waveforms: (1) applanation tonometry over the radial or carotid arteries, or ultrasound (2) oscillometric methods, using a standard BrBP cuff, to capture the brachial artery waveform at or near diastolic pressure. ${ }^{19}$ Conventional BrBP measurements are required to calibrate the arterial waveforms acquired by tonometry or oscillometry to yield a radial artery pressure waveform. For radial tonometry, BrBP is measured using a conventional cuff-based device before proceeding with tonometry while the patient is seated or supine, and a minimal amplification between brachial and radial arteries is assumed. For carotid tonometry, carotid waveforms are calibrated to mean and diastolic pressure based on the principle that mean and diastolic pressure remain relatively constant across the larger conduit arteries of the circulation. In the case of the cuff-based oscillometric method, the BrBP is measured contemporaneously with brachial arterial waveform acquisition, thereby overcoming concerns regarding brachial-radial amplification. ${ }^{3,13,21}$ Currently there are three main approaches to noninvasively derive CAP from predominantly radial or brachial arterial pressure waveforms: 1) the use of a generalized transfer function or mathematical modeling to process waveforms acquired using volume plethsymography or applanation tonometry ${ }^{21} ; 2$ ) identification of an inflection point on the descending slope of the systolic pressure wave, called the secondary systolic wave (SBP2) method; and 3) the $\mathrm{N}$-point moving average (NPMA) method. ${ }^{3,13}$

Recently published reviews on various non-invasive central BP devices have discussed in great detail waveform recording and calibration techniques, clinical applicability, validation, and the respective strengths and limitations of different devices. ${ }^{21-26}$ Tonometry over the carotid artery or reconstruction of the CAP wave form using a radial-to-aortic transfer function (SphygmoCor) are currently considered to be the gold standard methods for non-invasive CAP measurement (Fig. 1). ${ }^{23}$ The BPro wrist device (HealthStats, Singapore) derives CAP from noninvasively acquired radial artery pressure waveforms using an $\mathrm{N}$-point moving average method which acts as a simplified transfer function. ${ }^{27}$

Brachial oscillometric devices use brachial cuff oscillometric waveform measurement and a specific brachial pulse volume waveform transfer function to derive CAP (e.g. Mobil-O-Graph, SphygmoCor XCEL, WatchBP Office, Vicorder, CardioMon). The Pulsecor device (Arteriograph) uses another method consisting of analyzing the oscillometric waveform and using the amplitude of the late second systolic shoulder to derive CAP. The oscillometric method with a generalized transfer function and the NPMA method allow for 24-h central systolic pressure monitoring. Compared to the radial approach, using the brachial cuff-based approach allows results to be free of the brachial to radial amplification phenomena. However, these devices cannot overcome the inherent inaccuracy of cuff-based techniques. $^{21}$

Other parameters to estimate central hemodynamics and stiffness include Alx, PWV, cardio-ankle vascular Index (CAVI) and ambulatory arterial stiffness index (AASI):

\section{CAP-related indices}

- Augmentation Pressure (AP): The height of the late systolic peak above the inflection point defines the augmentation pressure. Simply, AP is the pressure difference $(\mathrm{mmHg})$ between the second and first systolic peaks of the aortic waveform. The first peak (or inflection point) is thought to correspond to the peak of the outgoing pressure wave, whilst the second peak is attributed to the effects of pressure wave reflections augmenting the outgoing pressure wave in late systole (Fig. 2).

- Augmentation Index (Alx) is the augmentation pressure expressed as a percentage of the waveform pulse pressure. Alx is one way to assess global wave reflections. ${ }^{26}$

- Pulse pressure amplification (PPA) is defined as the ratio of peripheral to central pulse pressure.

- Wave separation analysis (WSA) uses (aortic) pressure and flow to separate pressure waveforms into their forward and backward (reflected) waves.

\section{Aortic stiffness-related indices}

- Arterial stiffness is defined as stiffening of large vessels and is measured using PWV: velocity of the pulse wave along a length of artery, measured as a distance/time $(\mathrm{m} / \mathrm{s})$. Carotid to femoral PWV is the preferred method to assess arterial stiffness non-invasively. ${ }^{28}$

- Ambulatory arterial stiffness index (AASI) is derived from individual ambulatory blood pressure monitoring (ABPM) recordings and evaluates the relationship between diastolic and systolic BP over a $24 \mathrm{~h}$ period. The AASI index is calculated according the formula: 1 -s (the regression slope of diastolic pressure on systolic BP). In theory the stiffer the arterial tree the greater decline in slope or an increase in the AASI.

- Cardio-Ankle Vascular Index (CAVI) is an index reflecting whole body stiffness of the arterial system from the heart to ankles. CAVI is related to the established arterial stiffness parameter $\beta$ and is obtained by recording the distance from the level of the aortic valve (ie, brachial level) to the measuring point (ie, the ankle) and the time delay between the closing of the aortic valve to the detected change in arterial pressure wave at the set point. One of the advantages of CAVI assessment of arterial stiffness is that it is not affected by changes in BP, unlike cfPWV.

Key practical aspects of implementing CAP measurement based on our clinical experience are listed below. These are based on extensive experience with the SphygmoCor and BPro devices from the aliskiren development programme. More recently, additional experience with the SphygmoCor Excel device has been gained in the PARAMETER study, a study in hypertensive patients using the new drug sacubitril/valsartan (LCZ696). 


\section{Key practical aspects of implementing CAP measurement}

Selection of the device

- Selection of the device should be driven based on what needs to be measured and also the accuracy and validation aspects

Training

- Training of the investigators at the investigator meetings which is critical not only to get quality data but also to minimize the intra-and inter-operator variability

Quality control (Qc) aspects

- The Qc aspects are critical to increase the quality and limit the variability of the measurements at a given visit and between visits;

- Qc is part of the algorithm but should be done by independent cardiologists who should not only review the data but also the individual pulse wave forms and regular feed-back should be given to the centre to improve quality etc.

Overall, measurement of central BP was successful in many multi-centre trials with aliskiren and change from baseline in central SBP closely tracked the change from baseline in brachial SBP (difference $\sim 1.5 \mathrm{mmHg}$ ). Thus, changes in central BP closely track changes in brachial SBP as shown in Table 1.

\section{Central aortic pressure as a predictor of clinical outcome}

There is growing evidence indicating that CAP is more closely associated with traditional CV risks and arteriosclerotic target organ damage than BrBP. Moreover, aortic stiffness, a major determinant of CAPP, has been shown to be predictive of $\mathrm{CV}$ events beyond BrBP. Several prospective observational studies showed the predictive value of CAP parameters for CV events ${ }^{29}$ in a general population, ${ }^{10,30}$ patients with kidney disease, ${ }^{8,31-33}$ CAD, ${ }^{14,34,35}$ or elderly. ${ }^{15}$ The results from these studies are summarized in Table 2.

\section{General population}

In the Strong Heart Study, measurement of CAP in 2403 CVD-free American Indians who were followed for 4.8 years, showed that CAPP was a better predictor of fatal and nonfatal CV events than brachial PP, independent of conventional risk factors. ${ }^{12}$ A subsequent study of the same population with a longer follow-up (5.6 years), reconfirmed the predictive superiority of central over brachial pressure. ${ }^{36}$ Similar results were observed in a cohort of normotensive and untreated hypertensive elderly individuals. ${ }^{15}$ A study of the prognostic significance of CAP evaluated in an Asian population showed that central systolic and pulse pressure measurements, but not brachial pressure measurements, predicted 10 -year CV mortality. ${ }^{30}$ A Multiethnic Study of Atherosclerosis (MESA) in an ethnically diverse population (White, African American, Hispanic or Chinese) free of clinically apparent CV disease, showed that reflection magnitude was independently associated with incident CVE and strongly associated with incident CHF. Arterial wave reflections represent an important novel risk factor for CHF and a potential therapeutic target for primary CHF prevention. ${ }^{37}$ In a subsequent study in the same cohort, late systolic hypertension was shown to be strongly associated with incident HF. ${ }^{38}$

Vlachopoulos (2010) published a meta-analysis of eleven longitudinal studies in 5648 subjects with hypertension, ESRD, CAD, and in the general population. The results of the analysis showed a $9 \%$ increase in the risk of a CV event for every $10 \mathrm{mmHg}$ increase in CAP. Likewise a $10 \mathrm{mmHg}$ increase in CAPP was associated with a $14 \%$ increase in CV event risk and an increase in Alx of $10 \%$ was associated with
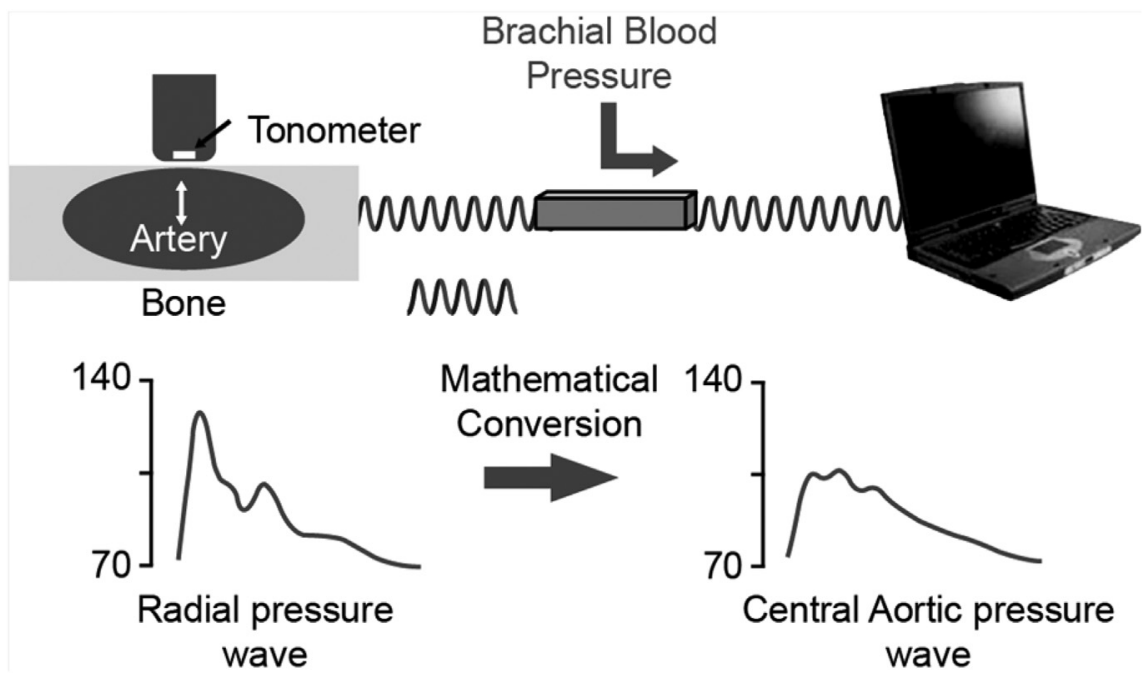

Figure 1 Deriving CAP from the radial pulse wave. 


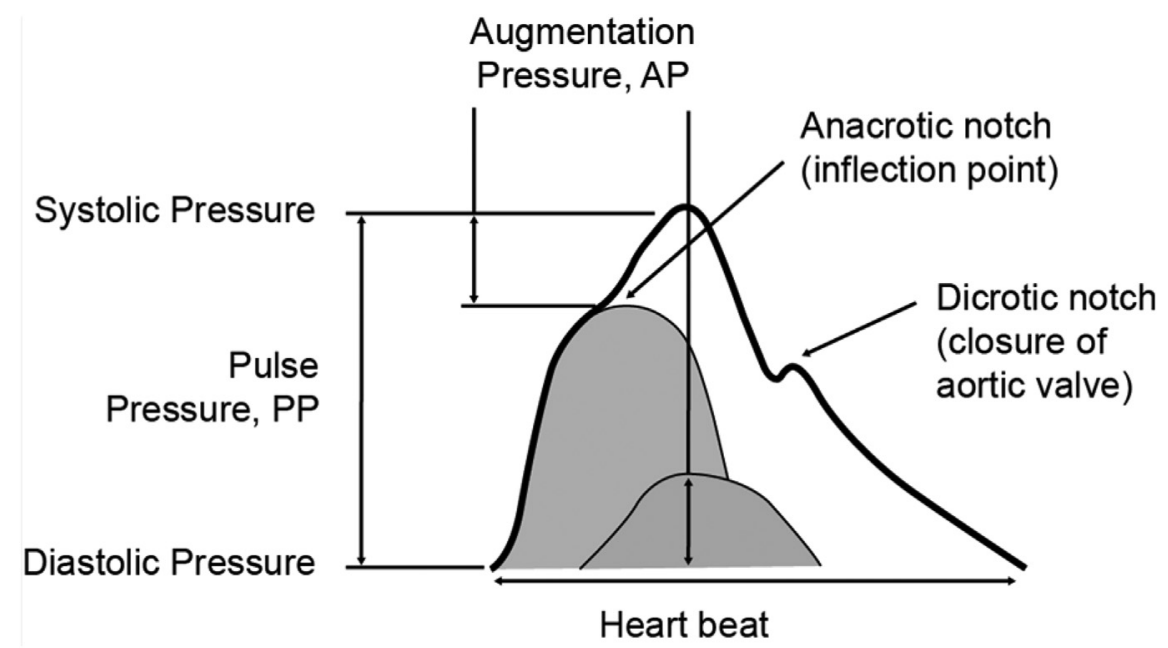

Figure 2 Central pressure wave form.

\begin{tabular}{|c|c|c|c|c|c|c|c|c|c|c|c|}
\hline \multirow[t]{2}{*}{$\begin{array}{l}\text { CASP } \\
\text { studies }\end{array}$} & & \multirow[t]{2}{*}{$\begin{array}{l}\text { Alis Dose } \\
(\mathrm{mg})\end{array}$} & \multirow[t]{2}{*}{$\begin{array}{l}\text { Comparator } \\
\text { Dose (mg) }\end{array}$} & \multirow[t]{2}{*}{$\begin{array}{l}\text { Duration } \\
\text { (wks) }\end{array}$} & \multicolumn{2}{|c|}{$\begin{array}{l}\text { Peripheral SBP } \\
\text { Change }(\mathrm{mmHg})\end{array}$} & \multirow[t]{2}{*}{$\begin{array}{l}\text { Diff } \\
(\mathrm{mmHg})\end{array}$} & \multicolumn{2}{|c|}{$\begin{array}{l}\text { Central SBP } \\
\text { Change }(\mathrm{mmHg})\end{array}$} & \multirow{2}{*}{$\begin{array}{l}\text { Diff } \\
(\mathrm{mmHg})\end{array}$} & \multirow[t]{2}{*}{$\begin{array}{l}+ \text { Central } \\
\text { BP }(\mathrm{mmHg})\end{array}$} \\
\hline & & & & & Alis & Comparator & & Alis & Comparator & & \\
\hline SPP2344 & $\begin{array}{l}\text { Alis/HCTZ/ } \\
\text { Aml vs Ram }\end{array}$ & $\begin{array}{l}300 \pm \\
(12.5 \\
-25) \pm \\
(5-10)\end{array}$ & $\begin{array}{l}10 \pm \\
(12.5-25) \pm \\
(5-10)\end{array}$ & 36 & -22.9 & -20.6 & -2.3 & -20.9 & -18.3 & -2.6 & 0.3 \\
\hline SPPUSO $7^{72}$ & $\begin{array}{l}\text { Alis/HCTZ } \\
\text { vs Ram }\end{array}$ & $300 / 25$ & 10 & 8 & -27.9 & -16.4 & -11.5 & -21.7 & -13.3 & -8.4 & -3.1 \\
\hline SPP2 $2409^{73}$ & $\begin{array}{l}\text { Alis/HCTZ } \\
\text { vs Aml }\end{array}$ & $300 / 25$ & 10 & 8 & -28.8 & -26.2 & -2.6 & -27.7 & -25 & -2.7 & 0.1 \\
\hline $\mathrm{SPPUSO}^{74}$ & $\begin{array}{l}\text { Alis/HCTZ } \\
\text { vs Aml }\end{array}$ & $300 / 25$ & 10 & 8 & -28.6 & -28.2 & -0.4 & -30.1 & -21.2 & -8.9 & 8.5 \\
\hline SPAUS01 ${ }^{75}$ & $\begin{array}{l}\text { Alis/Aml } \\
\text { vs Aml }\end{array}$ & $300 / 10$ & 10 & 8 & -34.1 & -28.9 & -5.2 & -29.8 & -24.2 & -5.6 & 0.4 \\
\hline Average & & & & & -28.5 & -24.1 & -4.4 & -26.0 & -20.4 & -5.6 & 1.2 \\
\hline
\end{tabular}

Alis: aliskiren; Aml: amlodipine; CASP: central aortic systolic pressure; HCTZ: hydrochlorothiazide; Ram: Ramipril; SBP: systolic blood pressure. BP change represents least square mean difference evaluated using an ANCOVA model.

Bold values show the difference between Aliskiren and comparator for BP change (brachial and central). Bold also shows where the difference (Aliskiren minus comparator) favours the change in brachial over central BP (last column).

a $32 \%$ increase in the $\mathrm{CV}$ event risk and a $38 \%$ increased risk of death from all causes. ${ }^{11}$ The Dublin outcome study showed that central hemodynamic indices such as AASI derived from ambulatory blood pressure predicted CV events in patients with CV risk and offers new insights into arterial stiffness. ${ }^{39}$ In a multicenter study, aortic PP was significantly correlated with the presence and extent of CAD in patients without antihypertensive therapy. ${ }^{40}$ In hypertensive and normotensive subjects, 24-h ambulatory central BP may be a better predictor of CV risk than office BrBP. ${ }^{41}$

\section{Epidemiological/observational evidence}

Patients with renal disease

Patients with chronic kidney disease (CKD) are at greatly increased risk for CV disease. Hypertension is both a cause and effect of chronic kidney disease (CKD). Hypertension causes functional and structural changes in the kidney and is a major risk factor for CV complications. A longitudinal study by London et al. was the first study to demonstrate an adverse impact of increased arterial wave reflection on CV prognosis in patients with end-stage renal disease (ESRD). ${ }^{33}$ In the same ESRD cohort, Safar et al. demonstrated that an increase in carotid PP was associated with $40 \%$ increase in all-cause mortality. ${ }^{8}$ In patients with mild to moderate CKD, CAPP predicted progression to ESRD significantly and independently of other risk factors. ${ }^{32}$ A prospective study in patients with CKD stages $2-4$, showed that CASP derived from brachial mean and diastolic pressure calibration provides independent, and on top of brachial systolic pressure, prognostic value in the prediction of all-cause mortality. ${ }^{42}$ In summary, currently available data indicate that elevated CAPP resulting from increased peripheral wave 
Table 2 Studies on predictive value of central BP parameters for CV events.

\begin{tabular}{|c|c|c|c|c|}
\hline Source & Population & $\mathrm{N}$ & Central BP parameter & End point \\
\hline London et al. $2001^{33}$ & ESRD & 180 & Carotid Alx & All-cause mortality and CV mortality \\
\hline Safar et al. $2002^{8}$ & ESRD & 180 & $\begin{array}{l}\text { Carotid PP, PP } \\
\text { amplification }\end{array}$ & All-cause mortality and CV mortality \\
\hline Briet et al. $2011^{32}$ & CKD & 180 & Carotid PP & Hemodialysis \\
\hline Weber et al. $2004^{76}$ & Suspected CAD & 465 & Aortic AP, Alx & Incident CAD \\
\hline Weber et al. $2005^{9}$ & $\mathrm{CAD}-\mathrm{PCl}$ & 262 & Radial Alx@Hr75 & CV events \\
\hline Weber et al. $2010^{35}$ & $\begin{array}{l}\text { CAD-coronary } \\
\text { angiography }\end{array}$ & 520 & Radial Alx & CV events \\
\hline Chirinos et al. $2005^{34}$ & CAD & 297 & Aortic AP, Alx & CV mortality and events \\
\hline Jankowski et al. $2004^{14}$ & CAD & 1109 & Aortic PP & CV events \\
\hline Roman et al. $2000^{77}$ & General & 266 & Carotid systolic BP & Relative LV wall thickness \\
\hline Roman et al. $2007^{12}$ & General & 2403 & Aortic PP & Carotid IMT and mass \\
\hline Roman et al. $2009^{36}$ & General & 2405 & Aortic PP & CV events \\
\hline Pini et al. $2008^{15}$ & General & 398 & Carotid PP & CV events \\
\hline Wang et al. $2009^{30}$ & General & 1272 & Carotid PP & CV mortality \\
\hline Chirinos et al. $2012^{37}$ & General & 5960 & Alx, RM or PPA & CVE and CHF \\
\hline Chirinos et al. $2015^{38}$ & General & 6124 & $\mathrm{~L} / \mathrm{E}_{\mathrm{SPTI}}$ & $\mathrm{HF}$ \\
\hline Williams et al. $2006^{17}$ & Hypertensive & 2073 & Aortic PP & CVE and procedures, plus renal impairment \\
\hline
\end{tabular}

AP: augmented pressure; Alx: augmentation index; Alx@Hr75: Alx adjusted for heart rate of 75 bpm; BP: blood pressure; CAD: coronary artery disease; CKD: chronic kidney disease; CV: cardiovascular; CVE: cardiovascular event; CHF: congestive heart failure; ESRD: endstage renal disease; HF: heart failure; L/E $\mathrm{E}_{\mathrm{SPTl}}$ : late/early systolic pressure-time integral ratio; LV: left ventricular PP: pulse pressure; PPA: pulse pressure amplification; PCl: percutaneous coronary intervention; RM: reflection magnitude $=$ [Reflected/Forward wave amplitude] $\times 100$.

reflection predisposes to subsequent major $\mathrm{CV}$ and renal events in patients with various stages of CKD.

\section{Patients with coronary heart disease}

Left ventricular afterload and coronary circulation are determined by CAP. Weber (2010) showed that adjusted Alx was significantly predictive for the primary endpoint of death, myocardial infarction and restenosis in patients with CAD undergoing $\mathrm{PCl} .^{35}$ In a prospective study in 297 CAD patients undergoing coronary angiography, Chirinos (2005) found that the aortic augmentation pressure as well as Alx predicted major adverse CV events in male CAD subjects undergoing coronary angiography. ${ }^{34}$ This finding was further strengthened by Jankowski (2008) who showed that CAPP was a powerful predictor of $\mathrm{CV}$ events in CAD patients. ${ }^{14}$ This evidence clearly indicates that increased and/or premature wave reflection and the resultant widened CAPP, are associated with worse long-term prognosis in CHD. Further, the Japan morning surge 1 study showed that CAPP measurement may be more important to assess cardiac load than BrPP in patients with hypertension. ${ }^{43}$

\section{Clinical trial evidence}

Large, randomized controlled trials such as ASCOT (AngloScandinavian Cardiac Outcomes Trial) and the LIFE (The Losartan Intervention For Endpoint reduction) study suggested that drugs like angiotensin converting enzyme inhibitors (ACEls) and angiotensin-receptor blockers (ARBs) may have effects on arterial stiffness that are beyond the effect on BP. ${ }^{44,45}$ Further, the clinical value of central BP was demonstrated in ASCOT-CAFE (Conduit Artery Function Evaluation). The main ASCOT trial reported a more favorable CV outcome in hypertensive patients treated with an amlodipine-based treatment regimen relative to an atenolol-based treatment regimen. In the CAFE sub study, amlodipine-based treatment had a significantly greater effect than atenolol-based treatment in reducing CAP whilst BrBP did not differ between treatments. CAPP was also shown to be a predictor of cardiovascular events in this study. ${ }^{46}$ The REASON study showed that the remodeling effect of a combination regimen with perindopril/indapamide on arterial properties (reflection coefficient) was still active even after 9 months of treatment, but without further reduction of peripheral blood pressure at the same time. ${ }^{47}$

\section{Guidelines on the measurement of CAP in the context of hypertension management}

Great emphasis has been placed on the role of arterial stiffness in the development of CV disease. According to ESC guidelines, evidence of arterial stiffness indicates subclinical organ damage and puts the patient into a higher risk category. For these reasons, arterial stiffness measurement is increasingly used in the clinical assessment of hypertensive patients. The majority of guidelines stress the importance of PP measurement specifically, including the key American, European, Latin American and Japanese guidelines, ${ }^{28,48-50}$ however they do not provide treatment recommendations for CAP. ESC/ESH 2013, AHA 2015 and JSH 2014 make a strong recommendation for the measurement of PWV, as shown in Table 3. Guidelines have shown that arterial stiffness, assessed by carotid-femoral PWV or indirectly by $P P$ is an independent predictor of $C V$ disease in adults. 
Table 3 Existing guidelines on CAP.

\begin{tabular}{|c|c|c|}
\hline Guideline & PP & PWV \\
\hline $\begin{array}{l}\text { AHA Scientific } \\
\text { statement } \\
(2015)^{28}\end{array}$ & NA & $\begin{array}{l}\text { - Arterial stiffness should be determined non- } \\
\text { invasively by measurement of cf-PWV } \\
\text { - ba-PWV or CAVI is useful in predicting cardio- } \\
\text { vascular outcomes in Asian populations } \\
\text { - Carotid-radial PWV is not recommended for } \\
\text { predicting outcomes }\end{array}$ \\
\hline JSH $(2014)^{50}$ & $\begin{array}{l}\text { - PP is a strong predictor of CVD } \\
\text { - Systolic and mean BPs have a greater predictive } \\
\text { power for occurrence of stroke than PP }\end{array}$ & $\begin{array}{l}\text { - PWV examination recommended among the ex- } \\
\text { amination parameters for target organ damage. } \\
\text { Cf-PWV, ba-PWV or CAVI may be measured, with } \\
\text { ba-PWV measurement being performed } \\
\text { routinely } \\
\text { - High ba-PWV ( } \geq 1800 \mathrm{~cm} / \mathrm{s}) \text { is predictive factor } \\
\text { for the onset of CVD }\end{array}$ \\
\hline ESC/ESH $2013^{49}$ & $\begin{array}{l}\text { - PP listed among the prognostic factors used for } \\
\text { stratification of total CV risk }-\mathrm{PP} \geq 60 \mathrm{~mm} \mathrm{Hg} \text { in } \\
\text { the elderly may be indicative of asymptomatic } \\
\text { organ damage }\end{array}$ & $\begin{array}{l}\text { - Cf-PWV is 'gold-standard' for measuring aortic } \\
\text { stiffness. Cf-PWV }>10 \mathrm{~m} / \mathrm{s} \text { indicative of } \\
\text { asymptomatic organ damage } \\
\text { - Arterial stiffness measured by PWV is among the } \\
\text { list of markers with high CV predictive value } \\
\text { - PWV is highly sensitive marker of organ damage } \\
\text { with limited data to support its prognostic value } \\
\text { - Cf-PWV should be considered to detect large } \\
\text { artery stiffening; in pts with PWV }>10 \mathrm{~m} / \mathrm{s} \text { all } \\
\text { antihypertensives can be considered provided } \\
\text { BP }<140 / 90 \text { is achieved (Ila-B) } \\
\text { - No properly powered RCTs but meta-analysis of } \\
\text { RCTs have shown ACEls, ARBs reduce PWV, } \\
\text { independent of BP reductions }\end{array}$ \\
\hline LASH $(2013)^{48}$ & - $\mathrm{PP}>65 \mathrm{mmHg}$ is associated with greater stiff- & 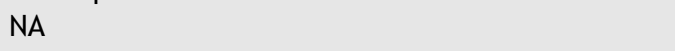 \\
\hline
\end{tabular}

ness of large arteries and increased CV morbidity and mortality

KDIGO (BP in CKD) $(2012)^{78}$

ACCF/AHA
(elderly)
$(2011)^{79}$

NKF-KDOQI (CVD in
dialysis
patients)
$2005^{80}$

- Measurement of PP or PWV can offer insights into vascular structure and function but was not able to make any evidence-based recommendations due to paucity of relevant data

- Achieving BP goal would require multiple drugs in pts with CKD and diabetes, particularly those with high PP

- PP increases with age, is a measure of degree of age-related vascular stiffness, and emerges as a potent risk factor for CAD events in older individuals

- PP identified as a stronger risk factor than SBP, $\mathrm{DBP}$, or mean pressure in older adults in some studies

- All dialysis patients should have PP determined monthly before dialysis

- PP, particularly in middle-aged and older subjects, is an independent predictor of risk of coronary heart disease, compared with mean arterial pressure
- Arterial stiffness should be determined non-

vascular outcomes in Asian populations

Carotid-radial PWV is not recommended for amination parameters for target organ damage. Cf-PWV, ba-PWV or CAVI may be measured, with ba-PWV measurement being performed

for the onset of CVD

Cf-PWV is 'gold-standard' for measuring aortic stiffness. Cf-PWV $>10 \mathrm{~m} / \mathrm{s}$ indicative of

Arterial stiffness measured by PWV is among the list of markers with high CV predictive value

PWV is highly sensitive marker of organ damage antihypertensives can be considered provided BP $<140 / 90$ is achieved (Ila-B)

RCTs have shown ACEls, ARBs reduce PWV NA

- PWV may be increased in early CKD but its impact on CVD risk and kidney disease prognosis is unclear

NA

- Arterial stiffness can be assessed by measurement of PWV

ACEI: angiotensin converting enzyme inhibitor; ACCF: American College of Cardiology Foundation; AHA: American Heart Association; ARB: angiotensin receptor blocker; ba: brachial/ankle; CAVI: cardio-ankle vascular index; CAD: coronary artery disease; Cf: carotid/ femoral; CKD: chronic kidney disease; CVD: Cardiovascular disease; DBP: diastolic blood pressure; ESC/ESH: European Society of Cardiology/European Society of Hypertension; JSH: Japanese Society of Hypertension; KDIGO: Kidney Disease: Improving Global Outcomes; LASH: Latin American Society of Hypertension; NKF-KDOQI: National Kidney Foundation- Kidney Disease Outcomes Quality Initiative; PP: pulse pressure; PWV: pulse wave velocity; RCTs: randomized clinical trials; SBP: systolic blood pressure. 


\section{Differential effect of antihypertensive treatments on central aortic pressure}

Antihypertensive drugs such as renin-angiotensin blockers and/or calcium antagonists are more potent than betablockers (BBs) and/or diuretics for lowering CASP even after adjusting for brachial systolic blood pressure (BrSBP). ${ }^{51,52}$ Beyond the importance of predicting CV disease, knowledge of central pressure may provide guidance in the choice of antihypertensive therapy. ${ }^{53}$ Treatment with different classes of antihypertensive drugs might have similar effects on BrBP and differential effects on CAP. ${ }^{54}$ This is evident for BBs, mainly atenolol, which are less effective than other classes of antihypertensives at lowering CAP for any given change in BrBP. This lack of effectiveness at reducing CAP is largely due to the heart rate-lowering effect of BBs, which reduces PPA. ${ }^{17}$ The EXPLOR study showed that CASP decreased significantly more in the amlodipine-valsartan group than in the amlodipine-atenolol group, despite similar changes in BrSBP. ${ }^{55}$ RAS inhibitor-based combination therapy with CCB or with diuretics based on the 24-h ambulatory BP profile and arterial properties, may achieve more individualized and ideal 24-h BP control in high-risk hypertensive patients. ${ }^{56}$

A review article by Protogerou (2009) summarized the effects of different classes of antihypertensive drugs on CAP beyond peripheral blood pressure. This review reported that newer antihypertensive drugs (ACEls, ARBs and CCBs) as well as nitrates have a more beneficial effect on pressure amplification than older drugs (diuretics and BBs). It also reported compelling evidence regarding the relative detrimental effect of BBs (mainly atenolol) on CAP and convincing evidence that ACEls increase pressure amplification. ${ }^{57,58} \mathrm{~A}$ metaanalysis of the comparative effects of different classes of antihypertensive drugs showed that reduction of BrSBP was larger than CASP with each class of drug. In placebo-adjusted drug vs. drug comparison, treatment with $\mathrm{BB}$, omapatrilat (although treatment with omapatrilat did produce the biggest fall in PPA seen to date) and thiazide diuretics lowered CASP significantly less than BrSBP (i.e. central to brachial amplification decreased), whereas other monotherapies lowered CASP and BrSBP to similar extents. ${ }^{59}$

Table 4 summarizes the results from the studies evaluating the effects of different classes of antihypertensive drugs as monotherapy or in combination on CAP. Recent studies with newer, more selective vasodilating BB agents, such as nebivolol, carvedilol, and celiprolol, demonstrated these agents to have a greater capacity to reduce CASP than traditional BBs because of their additional vasodilatory property that reduces the influence of wave reflections. The reduction in wave reflections seen with vasodilating BBs appears to offset the adverse heart rate-dependent increases in Alx seen with traditional BBs, such as atenolol. Moreover, the reduction in heart rate itself tends to be less with these vasodilating agents compared to atenolol.

\section{Discussion}

There is growing evidence to support the importance of CAP as a marker of risk and treatment efficacy. Individuals stratified by BrBP experienced a considerable overlap in CASP. Over $70 \%$ of individuals categorized as having 'highnormal' BrSBP had similar CASP to those with stage 1 hypertension. ${ }^{22}$ An individual patient data meta-analysis of prospective observational data from 22,433 subjects showed CASP to be a better predictor for future stroke than BrSBP, but not MI. ${ }^{60}$ Assessment of CASP may improve stroke prediction particularly in younger individuals. Hence measuring CAP in addition to BrBP may bring additional information and further characterize blood pressure patterns to improve treatment decisions. There is a need for large, well-designed trials to investigate whether lowering CASP will produce more benefit in terms of reduction in CV events than reduction in BrBP. Such trials should involve use of an agent that reduces CASP differentially to BrBP. Potential agents would include a nitrate or a nitrate/hydralazine combination.

Each of the non-invasive devices has its own limitations regarding methodological procedures, reproducibility and validity. Below are the practicalities of implementing CAP measurement in clinical trials. ${ }^{19,22,24,61}$

$>$ The currently available non-invasive techniques provide only an estimation of CAP and not a direct measurement. Thus new devices probably have to demonstrate good agreement with invasively measured CASP as the "gold standard".

$\gg$ Errors can occur by using inaccurate upper arm cuff BP values to calibrate the pressure waveforms.

$\triangleright$ Calibration errors of pressure waveforms with or without the use of transfer function.

$>$ Perception of error being introduced into CAP estimations by using a transfer function.

$>$ A small degree of amplification between the carotid artery and aorta might lead to over-estimation of CAP.

$\triangleright$ Applanation tonometry is highly operator-dependent, requires skill and experience and might be difficult to use routinely in a non-specialist setting.

$\triangleright$ Quality control issues on validity and inter-device variability.

$>$ Lack of consensus on standardization of CAP assessment methods. A consensus document for protocols to validate central pressure measurement devices is currently being written by a group from The Society for the Assessment of aRTErial structuRe and physiology (ARTERY). ${ }^{62}$

There are several studies such as ONTARGET (Ongoing Telmisartan Alone and in Combination With Ramipril Global Endpoint Trial), TRANS (TRanscend Arterial stiffNess Substudy), LAAS (Losartan Anti-Atherosclerosis Study), ADVANCED-J and PARAMETER (The Prospective comparison of Angiotensin Receptor neprilysin inhibitor with Angiotensin receptor blocker MEasuring arterial sTiffness in the eldERly) evaluating the effects of BP lowering treatment on arterial stiffness. Two large studies TRANS ${ }^{63}$ and ONTAR$\mathrm{GET}^{64}$ are still ongoing to evaluate the effects of telmisartan alone or in combination with ramipril. TRANS study would assess the beneficial effects of telmisartan on CV outcome and its relation to improvement in arterial stiffness. ONTARGET showed that telmisartan was equally 


\begin{tabular}{|c|c|c|c|c|}
\hline Source & Drug & Sample size & Result & Central parameters result \\
\hline \multicolumn{5}{|l|}{ ACEI } \\
\hline London G et al., 1994 & Perindopril & $\begin{array}{l}\text { 14, ESRD patients with } \\
\text { LVH }\end{array}$ & Positive & Decrease in central BP, aortic and arterial PWV \\
\hline Chen et al., 1995 & Fosinopril & 41, Hypertension & Positive & Lowered 24-hr ambulatory BP and normalized the elevated Alx \\
\hline London G et al., 1996 & Quinapril & $\begin{array}{l}12 \text {, Hypertension and } \\
\text { ESRD }\end{array}$ & Positive & Pronounced and sustained decrease in carotid SBP and PP \\
\hline $\begin{array}{l}\text { Mitchell GF et al., } 2002 \\
\text { (CHOIR study) }\end{array}$ & Enalapril & 87, Hypertension & Neutral & $\begin{array}{l}\text { Reduced significantly and to the same degree both peripheral and central SBP } \\
\text { and PP }\end{array}$ \\
\hline $\begin{array}{l}\text { Deary AJ et al., } 2002 \text { (ADLIB } \\
\text { study) }\end{array}$ & Lisinopril & 30, Hypertension & $\begin{array}{l}\text { Neutral/ } \\
\text { negative }\end{array}$ & $\begin{array}{l}\text { Reduced significantly and equally both brachial and aortic SBP in men. No } \\
\text { reduction in Alx, BNP and arterial stiffness }\end{array}$ \\
\hline Stokes GS et al., 2003 & Captopril & 11, Hypertension & Neutral & Decrease in aortic and brachial BP was similar with no reduction in Alx \\
\hline Morgan T et al., 2004 & $\begin{array}{l}\text { Enalapril or } \\
\text { Perindopril }\end{array}$ & 32, Hypertension & Positive & $\begin{array}{l}\text { Higher effect on central SBP and PP. Reduction in pressure wave reflections } \\
\text { and augmentation pressure }\end{array}$ \\
\hline Hirata K et al., 2005 & Ramipril & $\begin{array}{l}30, \text { Patients with } \\
\text { coronary risk factors }\end{array}$ & Positive & $\begin{array}{l}\text { Reduction in central BP, pressure wave reflections (Alx) and arterial stiffness } \\
\text { (PWV) }\end{array}$ \\
\hline $\begin{array}{l}\text { Dart AM et al., } 2007 \text { (ANBP2, } \\
\text { substudy) }\end{array}$ & Enalapril & 258, Hypertension & Positive & Reduction in central BP \\
\hline Aznaouridis K et al., 2007 & Captopril, Quinapril & $\begin{array}{l}25 \text { per group, } \\
\text { Hypertension }\end{array}$ & Positive & Decreased central BP and reduced Alx \\
\hline Jiang XG et al., 2007 & Enalapril & 46, Hypertension & Positive & Reduced aortic systolic, PP and Alx. \\
\hline Mackenzie et al., 2009 & Perindopril & $15, \mathrm{ISH}$ & Positive & Reduced central PP and Alx \\
\hline \multicolumn{5}{|l|}{ ARB } \\
\hline $\begin{array}{l}\text { Mahmud A, Feely } \\
\quad \text { J. } 2000\end{array}$ & Valsartan & 18, Hypertension & Positive & Reduced central BP and Alx \\
\hline Asmar 2001 & Telmisartan & $\begin{array}{l}\text { 23, Hypertension and } \\
\text { T2DM }\end{array}$ & Positive & Reduced carotid/femoral PWV, central BP and PP \\
\hline Stokes GS et al., 2003 & Eposartan & 11, Hypertension & Neutral & Decrease in aortic and brachial BP was similar with no reduction in Alx \\
\hline Dhakam Z et al., 2006 & Eposartan & 21, Hypertension & Positive & Reduced pressure wave reflections (Alx), aortic stiffness (cf-PWV) \\
\hline Aznaouridis K et al., 2007 & Telmisartan & 25, Hypertension & Neutral & No significant effect on central BP \\
\hline Schneider et al., 2008 & Irbesartan & 75, Hypertension & Positive & Preserved PP amplification and decreased Alx \\
\hline Kim et al. $2014^{81}$ & Losartan & 88, Hypertension & Positive & Reduced central BP, cf-PWV and Alx \\
\hline $\begin{array}{l}\text { Shimizu et al. } 2015^{82}(\mathrm{~J}- \\
\text { TOP) }\end{array}$ & Candesartan & 180 , Hypertension & Positive & Reduction in central SBP \\
\hline \multicolumn{5}{|l|}{ CCB } \\
\hline London G et al., 1994 & Nitredipine & $\begin{array}{l}\text { 10, ESRD patients with } \\
\text { LVH }\end{array}$ & Positive & Decrease in central BP, aortic and arterial PWV \\
\hline $\begin{array}{l}\text { Deary AJ et al., } 2002 \text { (ADLIB } \\
\text { study) }\end{array}$ & Amlodipine & 30, Hypertension & Neutral & $\begin{array}{l}\text { No change in pressure wave reflections, Alx was reduced in men, but not in } \\
\text { women. }\end{array}$ \\
\hline Morgan T et al., 2004 & $\begin{array}{l}\text { Amlodipine or } \\
\text { Felodipine }\end{array}$ & 32, Hypertension & Positive & Reduced Alx \\
\hline
\end{tabular}




\begin{tabular}{|c|c|c|c|c|}
\hline Source & Drug & Sample size & Result & Central parameters result \\
\hline Mackenzie et al., 2009 & Lercanidipine & 14 , ISH & Positive & Reduced central PP and Alx \\
\hline $\begin{array}{l}\text { Williams et al., } 2006 \text { (CAFE } \\
\text { study) }\end{array}$ & Amlodipine & 1042, Hypertension & Positive & Reduction in CAP, CAPP and Alx \\
\hline \multicolumn{5}{|l|}{ Diuretics } \\
\hline $\begin{array}{l}\text { Deary AJ et al., } 2002 \text { (ADLIB } \\
\text { Study) }\end{array}$ & Bendrofluazide & 30, Hypertension & Negative & Aortic SBP was not reduced, although brachial SBP was significantly reduced \\
\hline Morgan T et al., 2004 & Hydrochlorothiazide & 32 & Neutral & Reduced Alx \\
\hline Mahmud A, Feely J. 2005 & Bendroflumetazide & 24 & Neutral & Reductions in PWV and Alx were not significant \\
\hline $\begin{array}{l}\text { Dart AM et al., } 2007 \text { (ANBP2 } \\
\text { substudy) }\end{array}$ & Diuretics & 221 & Positive & Reduction in central BP \\
\hline Jiang XG et al., 2007 & Indapamide & 55, Hypertension & Neutral & No change in Alx \\
\hline Mackenzie et al., 2009 & Bendrofluazide & 13 , ISH & Positive & $\underline{\text { Reduced central PP }}$ \\
\hline \multicolumn{5}{|l|}{ Beta blockers } \\
\hline Chen et al., 1995 & Atenolol & 38, Hypertension & Negative & Lowered 24-hr ambulatory BP and lowered the elevated Alx \\
\hline $\begin{array}{l}\text { Asmar RG et al., } 2001 \\
\text { (REASON Study) }\end{array}$ & Atenolol & 202, Hypertension & Negative & Increased Alx \\
\hline $\begin{array}{l}\text { Deary AJ et l, } 2002 \text { (ADLIB } \\
\text { study) }\end{array}$ & Bisoprolol & 30, Hypertension & Negative & Reduced central BP and Increase Alx \\
\hline Morgan T et al., 2004 & Atenolol & 32, Hypertension & Negative & Greater rise in augmentation pressure and a larger Alx \\
\hline Hirata K et al., J 2005 & Atenolol & $\begin{array}{l}30, \text { Patients with } \\
\text { coronary risk factors }\end{array}$ & Negative & $\begin{array}{l}\text { Little change in either aortic or brachial systolic pressure and no significant } \\
\text { reduction in PWV }\end{array}$ \\
\hline Dhakam Z et al., 2006 & Atenolol & 21, Hypertension & Negative & Reduced PP amplification and pressure wave reflections (Alx) \\
\hline Schneider et al., 2008 & Atenolol & 81, Hypertension & Negative & Increased Alx and attenuated PP amplification \\
\hline Dhakam Z et al., 2008 & Nebivolol & $16, \mathrm{ISH}$ & Neutral & Reduction in central PP and less pronounced increase in Alx \\
\hline Dhakam Z et al., 2008 & Atenolol & 16, ISH & Negative & Increased central PP and significant increase in Alx \\
\hline Mahmud A, Feely J. 2008 & Nebivolol & 20, Hypertension & Positive & Increased PP amplification and reduction in augmentation pressure and Alx \\
\hline Mahmud A, Feely J. 2008 & Atenolol & 20, Hypertension & Negative & Decreased PP amplification and Alx \\
\hline Mackenzie et al., 2009 & Atenolol & $17, \mathrm{ISH}$ & Negative & No effect on central PP and Alx increased \\
\hline Kampus et al. $2011^{83}$ & Nebivolol & 30, Hypertension & Positive & Reduction in central BP and PP, Alx and PWV \\
\hline Kampus et al. $2011^{83}$ & Metoprolol & 33, Hypertension & Neutral & No significant change in Alx and PWV \\
\hline Soanker et al. $2012^{84}$ & Nebivolol & 13, Hypertension & Positive & Reduced CAP, Alx and cf-PWV \\
\hline Studinger et a. $2013^{85}$ & $\begin{array}{l}\text { Carvedilol, Nebivolol, } \\
\text { or Metoprolol }\end{array}$ & $21,21,18$, Hypertension & Neutral & Similar decreases in central BP with no significant alterations in Alx and PWV \\
\hline Zhou et al. $2013^{86}$ & Bisoprolol & 54, Hypertension & Positive & Reduced aortic PP and increased Alx \\
\hline Zhou et al. $2013^{86}$ & Atenolol & 55, Hypertension & Negative & $\begin{array}{l}\text { Increase in Aortic PP, and augmentation pressure and decrease in PP } \\
\text { amplification }\end{array}$ \\
\hline Redon et al. $2014^{87}$ & Nebivolol & 69, Hypertension & Neutral & Reduction in CAP and less pronounced impact on Alx \\
\hline Kim et al. $2014^{81}$ & Carvedilol & 94, Hypertension & Positive & Reduced central BP, cf-PWV and Alx \\
\hline $\begin{array}{l}\text { Williams et al., } 2006 \text { (CAFE } \\
\text { study) }\end{array}$ & Atenolol & 1031, Hypertension & Negative & Increase in central pressure and Alx \\
\hline
\end{tabular}




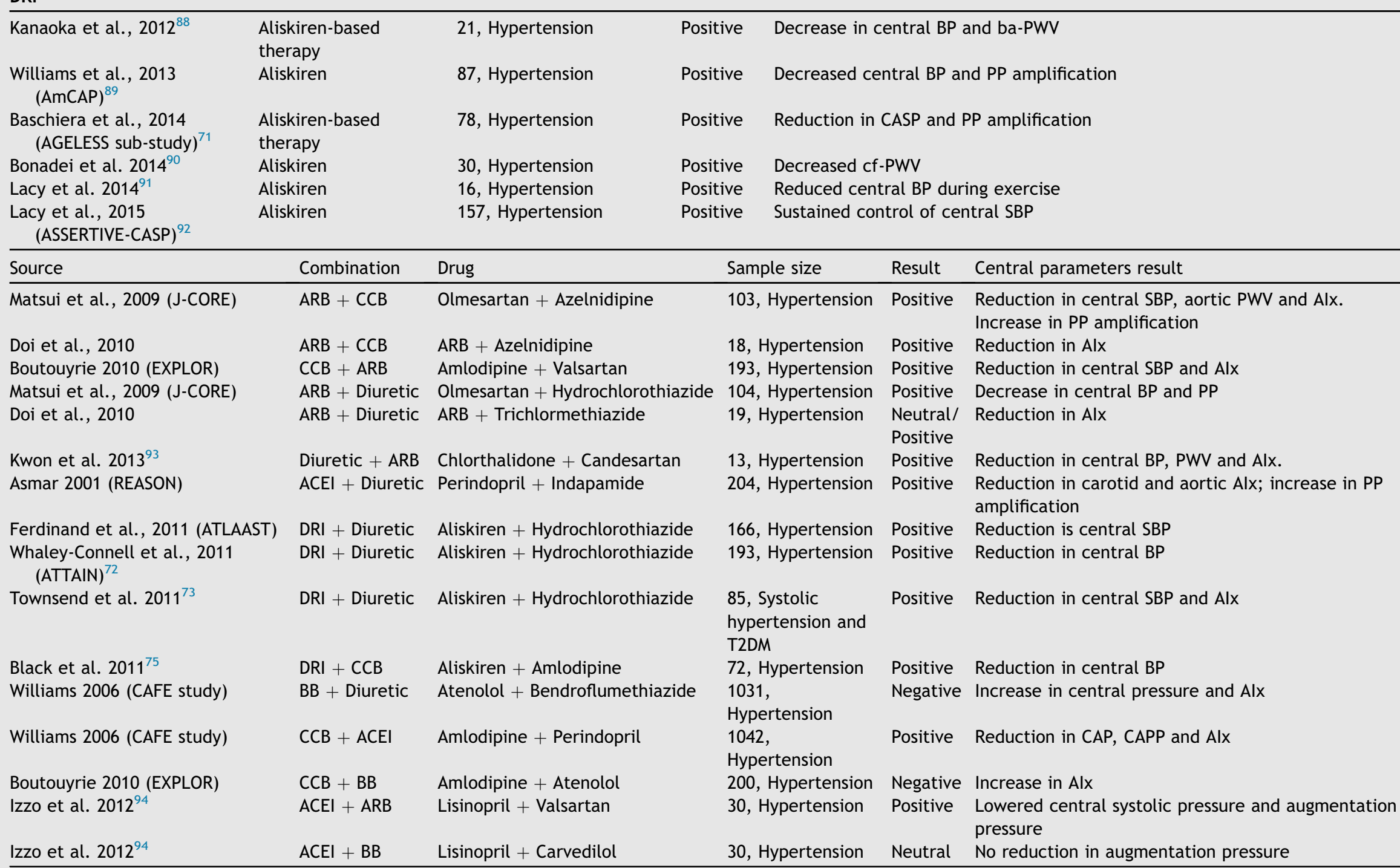

Data modified from Protogerou et al., 2009 and Manisty et al., 2013 (References are cited for studies which are additional to those cited in Protogerou et al., 2009 and Manisty et al., 2013). The studies are classified according to the antihypertensive class and effect (positive/negative/neutral) on central blood pressure, studies using monotherapy or combination treatment are included.

ACEI: angiotensin converting enzyme inhibitor; ARB: angiotensin receptor blocker; Alx: augmentation index; BP: blood pressure; BB: beta blocker; BNP: brain natriuretic peptide; ba-PWV: brachial/ankle pulse wave velocity; CAP: central aortic pressure; cf-PWV: carotid/femoral pulse wave velocity; DRI: direct renin inhibitor; ESRD: end stage renal disease; LVH: left ventricular hypertrophy; PP: pulse pressure; T2DM: type 2 diabetes mellitus.

Note: Data from the CAFE study is presented under both mono and combination therapy as treatment in ASCOT was initiated as monotherapy and many participants were up-titrated to combination therapy. 
effective to ramipril in patients with vascular disease or high-risk diabetes and was associated with less angioedema. The ADVANCED-J study is a prospective clinical study that was designed to compare the increase in dose of ARB and the combined use of amlodipine in terms of BP control in patients with diabetes and hypertension and whose BP levels are inadequately controlled by single treatment with an ARB. ${ }^{65}$ LAAS is a randomized, open-label, comparative, non-inferiority, multicenter study comparing the efficacy of losartan and carvedilol on arterial stiffness in patients with essential hypertension (ClinicalTrials.gov Identifier: NCT00496834).

PARAMETER is the first prospective randomized study showing that sacubitril/valsartan (LCZ696), the first ARNI, reduces CAP and CAPP more effectively than an ARB in high-risk, older patients with systolic hypertension and an increased PP. These results suggest that LCZ696 provides beneficial effects on central aortic hemodynamics and function that could provide a therapeutic advantage beyond those observed with RAS blockade alone. ${ }^{66}$

\section{Measurement of CAP from clinical trials to clinical practice}

Measurement of CAP in clinical practice is likely to have important implications for the future management of hypertension. The study by Chen (2013) represents an important step towards the application of the CAP concept to assess clinical risk for CVD. It showed that a CAP of 130/ $90 \mathrm{~mm} \mathrm{Hg}$ was the threshold for the diagnosis of hypertension and was characterized by a greater discriminatory power for CV mortality. ${ }^{67}$ A further study by Herbert (2014) provided the distributions of CAP values and amplification of BP in a normal population without $\mathrm{CV}$ risk factors and in a reference population with $\mathrm{CV}$ risk factors according to age and sex. ${ }^{68}$ Additionally, the recent approval of non-invasive CAP assessment by the Renal Physicians Association (US), to move CAP waveform analysis from Category III (tracking) to Category I (fully eligible for reimbursement) has been a significant step in the recognition of the value of CAP measurement. This latest development is expected to further accelerate the clinical adoption of CAP measurement and should contribute to improve BP management in the United States (AMA CPT Report). Future recognition, by regulatory bodies such as the FDA, of CASP as a surrogate end-point in hypertension trials should also help to accelerate this process. ${ }^{69}$

\section{Future directions for CAP research}

Robust data from large clinical trials/meta-analysis is required to show the value of CAP over BrBP in predicting CV outcomes, particularly outcomes relating directly to hemodynamic stress. Further data is also required to show that CAP provides added value for risk stratification to complement information provided by conventional BrBP. Such data may be acquired in younger people where amplification is particularly variable.

Data from clinical trials looking at CAP as a therapeutic target are warranted to further characterize the value of CAP as a new therapeutic target and to further distinguish antihypertensive drugs that may differentially influence CAP and BrBP. Large scale application of CAP measurement is now possible due to the ease of use of new devices making CASP measurement available to paramedic personnel in routine practice. This might allow potential assessment of the real life impact of clinical practice change. Development of self-measurement of CAP would also enable patients to measure CAP at home without the need for a specialist operator. Comparison of home CAP data against the newly arising technique of 24-h CAP measurement will also provide important data. Further data is also required from large cohort studies to establish firm threshold values for central pressure in the diagnosis of increased CAP across different ranges of BrBP where there is considerable overlap in CAP values. Information may also be collected to investigate whether such potential thresholds might be influenced by factors such as age or gender, known to influence pressure amplification. Moreover, the beneficial effects of lowering CAP to target treatment and the value of such treatment targets needs to be further established. A further logical development would be measurement of CAP with non-cuff based systems. Indeed, such systems are currently in development. ${ }^{70}$ CAP measurement may improve efficacy and safety in drug development. FDA considered the possibility of including CAP as a surrogate in anti-hypertensive drug trials, and makes the point that some non-cardiovascular drugs may increase CAP whilst having little effect on brachial pressure, antiretroviral drugs being a good example. ${ }^{69}$

\section{Funding}

This research received no specific grant from any funding agency in the public, commercial, or not-for-profit sectors.

\section{Conflicts of interest}

Dr Patrick Brunel, Dr Fabio Baschiera and Dr Dion Zappe were involved in the writing of this review; they are employees of Novartis and are therefore eligible for Novartis stock and stock options.

\section{Acknowledgements}

All authors participated in the development and writing of the paper, and approved the final manuscript for publication. The authors take full responsibility for the content of the paper and thank medical writer Madhavi Dokku (Novartis) for medical writing support, editorial assistance, collation and incorporation of comments from all authors.

\section{References}

1. Law M, Wald N, Morris J. Lowering blood pressure to prevent myocardial infarction and stroke: a new preventive strategy. Health Technol Assess 2003; 7:1-94.

2. Nichols WW, O'Rourke MF. In: MCDonald's blood flow in arteries. Theoretical, experimental and clinical principles. 5th Ed. London: Arnold E; 2005. p. 166-267. 
3. Williams B, Lacy PS. Central aortic pressure: the next frontier in blood pressure measurement? In: A.E. Berbari, G. Mancia, editors. Special issues in hypertension. Milan: Springer; 2012. p. $181-97$.

4. Avolio AP, Van Bortel LM, Boutouyrie P, Cockcroft JR, McEniery CM, Protogerou AD, et al. Role of pulse pressure amplification in arterial hypertension: experts' opinion and review of the data. Hypertension 2009;54:375-83.

5. McEniery CM, Yasmin, McDonnell B, Munnery M, Wallace SM, Rowe CV, et al. Central pressure: variability and impact of cardiovascular risk factors: the Anglo-Cardiff Collaborative Trial II. Hypertension 2008;51:1476-82.

6. McEniery CM, Yasmin, Hall IR, Qasem A, Wilkinson IB, Cockcroft JR. Normal vascular aging: differential effects on wave reflection and aortic pulse wave velocity: the AngloCardiff Collaborative Trial (ACCT). J Am Coll Cardiol 2005; 46:1753-60.

7. Yasmin Brown MJ. Similarities and differences between augmentation index and pulse wave velocity in the assessment of arterial stiffness. QJM 1999;92:595-600.

8. Safar ME, Blacher J, Pannier B, Guerin AP, Marchais SJ, Guyonvarc'h PM, et al. Central pulse pressure and mortality in end-stage renal disease. Hypertension 2002;39:735-8.

9. Weber T, Auer J, O’Rourke MF, Kvas E, Lassnig E, Lamm G, et al. Increased arterial wave reflections predict severe cardiovascular events in patients undergoing percutaneous coronary interventions. Eur Heart J 2005;26:2657-63.

10. Roman MJ, Okin PM, Kizer JR, Lee ET, Howard BV, Devereux RB. Relations of central and brachial blood pressure to left ventricular hypertrophy and geometry: the Strong Heart Study. $J$ Hypertens 2010;28:384-8.

11. Vlachopoulos C, Aznaouridis K, O'Rourke MF, Safar ME, Baou K, Stefanadis C. Prediction of cardiovascular events and all-cause mortality with central haemodynamics: a systematic review and meta-analysis. Eur Heart J 2010;31:1865-71.

12. Roman MJ, Devereux RB, Kizer JR, Lee ET, Galloway JM, Ali T, et al. Central pressure more strongly relates to vascular disease and outcome than does brachial pressure: the Strong Heart Study. Hypertension 2007;50:197-203.

13. Muiesan ML, Salvetti M, Bertacchini F, Agabiti-Rosei C, Maruelli G, Colonetti E, et al. Central blood pressure assessment using 24-hour brachial pulse wave analysis. J Vasc Diagn 2014; $2: 141-8$.

14. Jankowski P, Kawecka-Jaszcz K, Czarnecka D, BrzozowskaKiszka M, Styczkiewicz K, Loster M, et al. Pulsatile but not steady component of blood pressure predicts cardiovascular events in coronary patients. Hypertension 2008;51:848-55.

15. Pini R, Cavallini MC, Palmieri V, Marchionni N, Di BM, Devereux RB, et al. Central but not brachial blood pressure predicts cardiovascular events in an unselected geriatric population: the ICARe Dicomano Study. J Am Coll Cardiol 2008;51: 2432-9.

16. 2003 European Society of Hypertension-European Society of Cardiology guidelines for the management of arterial hypertension. J Hypertens 2003;21:1011-53.

17. Williams B, Lacy PS, Thom SM, Cruickshank K, Stanton A, Collier D, et al. Differential impact of blood pressure-lowering drugs on central aortic pressure and clinical outcomes: principal results of the Conduit Artery Function Evaluation (CAFE) study. Circulation 2006;113:1213-25.

18. Avolio A. Central aortic blood pressure and management of hypertension: confirmation of a paradigm shift? Hypertension 2013;62:1005-7.

19. Sharman JE, Marwick TH, Gilroy D, Otahal P, Abhayaratna WP, Stowasser M. Randomized trial of guiding hypertension management using central aortic blood pressure compared with best-practice care: principal findings of the BP GUIDE study. Hypertension 2013;62:1138-45.
20. Izzo Jr JL. Brachial vs. central systolic pressure and pulse wave transmission indicators: a critical analysis. Am J Hypertens 2014;27:1433-42.

21. Millasseau S, Agnoletti D. Non-invasive estimation of aortic blood pressures: a close look at current devices and methods. Curr Pharm Des 2015;21:709-18.

22. MCEniery CM, Cockcroft JR, Roman MJ, Franklin SS, Wilkinson IB. Central blood pressure: current evidence and clinical importance. Eur Heart J 2014;35:1719-25.

23. Narayan O, Casan J, Szarski M, Dart AM, Meredith IT, Cameron JD. Estimation of central aortic blood pressure: a systematic meta-analysis of available techniques. $J$ Hypertens 2014;32:1727-40.

24. Cheng HM, Lang D, Tufanaru C, Pearson A. Measurement accuracy of non-invasively obtained central blood pressure by applanation tonometry: a systematic review and meta-analysis. Int J Cardiol 2013;167:1867-76.

25. Weber T, Wassertheurer S. Moving on-on average in the right direction?: noninvasive methods to estimate central blood pressure. Hypertension 2014;63:665-7.

26. Mitchell GF. Does measurement of central blood pressure have treatment consequences in the clinical praxis? Curr Hypertens Rep 2015;17:66.

27. Williams B, Lacy PS, Yan P, Hwee CN, Liang C, Ting CM. Development and validation of a novel method to derive central aortic systolic pressure from the radial pressure waveform using an n-point moving average method. J Am Coll Cardiol 2011;57:951-61.

28. Townsend RR, Wilkinson IB, Schiffrin EL, Avolio AP, Chirinos JA, Cockcroft JR, et al. Recommendations for improving and standardizing vascular research on arterial stiffness: a scientific statement from the American Heart Association. Hypertension 2015;66:698-722.

29. Hashimoto J, Ito S. Central blood pressure and prediction of cardiovascular events. Curr Hypertens Rev 2012;8:108-13.

30. Wang KL, Cheng HM, Chuang SY, Spurgeon HA, Ting CT, Lakatta EG, et al. Central or peripheral systolic or pulse pressure: which best relates to target organs and future mortality? J Hypertens 2009;27:461-7.

31. Briet M, Bozec E, Laurent S, Fassot C, London GM, Jacquot C, et al. Arterial stiffness and enlargement in mild-to-moderate chronic kidney disease. Kidney Int 2006;69:350-7.

32. Briet M, Collin C, Karras A, Laurent S, Bozec E, Jacquot C, et al. Arterial remodeling associates with CKD progression. J Am Soc Nephrol 2011;22:967-74.

33. London GM, Blacher J, Pannier B, Guerin AP, Marchais SJ, Safar ME. Arterial wave reflections and survival in end-stage renal failure. Hypertension 2001;38:434-8.

34. Chirinos JA, Zambrano JP, Chakko S, Veerani A, Schob A, Willens $\mathrm{HJ}$, et al. Aortic pressure augmentation predicts adverse cardiovascular events in patients with established coronary artery disease. Hypertension 2005;45:980-5.

35. Weber T, O’Rourke MF, Lassnig E, Porodko M, Ammer M, Rammer M, et al. Pulse waveform characteristics predict cardiovascular events and mortality in patients undergoing coronary angiography. J Hypertens 2010;28:797-805.

36. Roman MJ, Devereux RB, Kizer JR, Okin PM, Lee ET, Wang W, et al. High central pulse pressure is independently associated with adverse cardiovascular outcome the strong heart study. $J$ Am Coll Cardiol 2009;54:1730-4.

37. Chirinos JA, Kips JG, Jacobs Jr DR, Brumback L, Duprez DA, Kronmal R, et al. Arterial wave reflections and incident cardiovascular events and heart failure: MESA (Multiethnic Study of Atherosclerosis). J Am Coll Cardiol 2012;60:2170-7.

38. Chirinos JA, Segers P, Duprez DA, Brumback L, Bluemke DA, Zamani $P$, et al. Late systolic central hypertension as a predictor of incident heart failure: the Multi-ethnic Study of Atherosclerosis. J Am Heart Assoc 2015;4:e001335. 
39. Dolan E, Staessen JA, O'Brien E. Data from the Dublin outcome study. Blood Press Monit 2007;12:401-3.

40. Danchin N, Benetos A, Lopez-Sublet M, Demicheli T, Safar M, Mourad JJ. Aortic pulse pressure is related to the presence and extent of coronary artery disease in men undergoing diagnostic coronary angiography: a multicenter study. Am J Hypertens 2004; 17:129-33.

41. Jankowski P, Bednarek A, Olszanecka A, Windak A, KaweckaJaszcz K, Czarnecka D. Twenty-four-hour profile of central blood pressure and central-to-peripheral systolic pressure amplification. Am J Hypertens 2013;26:27-33.

42. Wassertheurer S, Baumann M. Assessment of systolic aortic pressure and its association to all cause mortality critically depends on waveform calibration. J Hypertens 2015;33: 1884-9.

43. Matsui Y, Eguchi K, Shibasaki S, Ishikawa J, Hoshide S, Pickering TG, et al. Monitoring of the central pulse pressure is useful for detecting cardiac overload during antiadrenergic treatment: the Japan Morning Surge 1 study. J Hypertens 2008; 26:1928-34.

44. Dahlof B, Sever PS, Poulter NR, Wedel H, Beevers DG, Caulfield $M$, et al. Prevention of cardiovascular events with an antihypertensive regimen of amlodipine adding perindopril as required versus atenolol adding bendroflumethiazide as required, in the Anglo-Scandinavian Cardiac Outcomes TrialBlood Pressure Lowering Arm (ASCOT-BPLA): a multicentre randomised controlled trial. Lancet 2005;366:895-906.

45. Greve AM, Olsen MH, Bella JN, Lonnebakken MT, Gerdts E, Okin PM, et al. Contrasting hemodynamic mechanisms of losartan- vs. atenolol-based antihypertensive treatment: a LIFE study. Am J Hypertens 2012;25:1017-23.

46. Davies JE, Lacy P, Tillin T, Collier D, Cruickshank JK, Francis DP, et al. Excess pressure integral predicts cardiovascular events independent of other risk factors in the conduit artery functional evaluation substudy of Anglo-Scandinavian Cardiac Outcomes Trial. Hypertension 2014;64:60-8.

47. London GM, Asmar RG, O'Rourke MF, Safar ME. Mechanism(s) of selective systolic blood pressure reduction after a low-dose combination of perindopril/indapamide in hypertensive subjects: comparison with atenolol. J Am Coll Cardiol 2004;43:92-9.

48. Lopez-Jaramillo P, Sanchez RA, Diaz M, Cobos L, Bryce A, Parra Carrillo JZ, et al. Latin American consensus on hypertension in patients with diabetes type 2 and metabolic syndrome. $J$ Hypertens 2013;31:223-38.

49. Mancia G, Fagard R, Narkiewicz K, Redon J, Zanchetti A, Bohm M, et al. 2013 ESH/ESC practice guidelines for the management of arterial hypertension. Blood Press 2014;23: $3-16$.

50. Shimamoto K, Ando K, Fujita T, Hasebe N, Higaki J, Horiuchi M, et al. The Japanese Society of hypertension guidelines for the management of hypertension (JSH 2014). Hypertens Res 2014; 37:253-390.

51. Agabiti-Rosei E, Mancia G, O'rourke MF, Roman MJ, Safar ME, Smulyan H, et al. Central blood pressure measurements and antihypertensive therapy: a consensus document. Hypertension 2007; 50:154-60.

52. Dudenbostel T, Glasser SP. Effects of antihypertensive drugs on arterial stiffness. Cardiol Rev 2012;20:259-63.

53. Oparil S, Izzo Jr JL. Pulsology rediscovered: commentary on the conduit artery function evaluation (CAFE) study. Circulation 2006;113:1162-3.

54. Matsui Y, Kario K. Differential impacts of antihypertensive drugs on central blood pressure and their clinical significance. Curr Hypertens Rev 2012;8:114-9.

55. Boutouyrie P, Achouba A, Trunet P, Laurent S. Amlodipinevalsartan combination decreases central systolic blood pressure more effectively than the amlodipine-atenolol combination: the EXPLOR study. Hypertension 2010;55:1314-22.
56. Kario K. Proposal of RAS-diuretic vs. RAS-calcium antagonist strategies in high-risk hypertension: insight from the 24-hour ambulatory blood pressure profile and central pressure. J Am Soc Hypertens 2010;4:215-8.

57. Protogerou AD, Papaioannou TG, Lekakis JP, Blacher J, Safar ME. The effect of antihypertensive drugs on central blood pressure beyond peripheral blood pressure. Part I: (Patho)physiology, rationale and perspective on pulse pressure amplification. Curr Pharm Des 2009;15:267-71.

58. Protogerou AD, Stergiou GS, Vlachopoulos C, Blacher J, Achimastos A. The effect of antihypertensive drugs on central blood pressure beyond peripheral blood pressure. Part II: evidence for specific class-effects of antihypertensive drugs on pressure amplification. Curr Pharm Des 2009;15:272-89.

59. Manisty $\mathrm{CH}$, Hughes AD. Meta-analysis of the comparative effects of different classes of antihypertensive agents on brachial and central systolic blood pressure, and augmentation index. Br J Clin Pharmacol 2013;75:79-92.

60. McEniery C. Central blood pressure and cardiovascular risk: an individual participant meta-analysis of prospective observational data from 22,433 subjects. J Am Coll Cardiol 2015; 65(10_S). http://dx.doi.org/10.1016/S0735-1097(15)61464-4.

61. Papaioannou TG, Protogerou AD, Stamatelopoulos KS, Vavuranakis M, Stefanadis C. Non-invasive methods and techniques for central blood pressure estimation: procedures, validation, reproducibility and limitations. Curr Pharm Des 2009; 15:245-53.

62. Wilkinson IB, McEniery C, Schillaci G, Boutouyrie P, Segers P, Donald A. ARTERY Society guidelines for validation of noninvasive haemodynamic measurement devices: Part 1, arterial pulse wave velocity. Artery Res 2010;4:34-40.

63. Topouchian J, El Feghali R, Pannier B, Wang S, Zhao F, Smetana K, et al. Arterial stiffness and pharmacological interventions-the TRanscend arterial stiffNess Substudy (TRANS study). Vasc Health Risk Manag 2007;3:381-7.

64. Yusuf S, Teo KK, Pogue J, Dyal L, Copland I, Schumacher H, et al. Telmisartan, ramipril, or both in patients at high risk for vascular events. N Engl J Med 2008;358:1547-59.

65. Kawamori R, Daida H, Tanaka Y, Miyauchi K, Kitagawa A, Hayashi D, et al. Amlodipine versus angiotensin II receptor blocker; control of blood pressure evaluation trial in diabetics (ADVANCED-J). BMC Cardiovasc Disord 2006;6:39.

66. Williams B, Cockcroft JR, Kario K, Zappe DH, Wang Q, Guo W. Principal results of the prospective comparison of Angiotensin Receptor neprilysin inhibitor with Angiotensin receptor blocker MEasuring arterial sTiffness in the eldERly - PARAMETER study. In: Presented at ESC; 2015.

67. Cheng HM, Chuang SY, Sung SH, Yu WC, Pearson A, Lakatta EG, et al. Derivation and validation of diagnostic thresholds for central blood pressure measurements based on long-term cardiovascular risks. J Am Coll Cardiol 2013;62:1780-7.

68. Herbert A, Cruickshank JK, Laurent S, Boutouyrie P. Establishing reference values for central blood pressure and its amplification in a general healthy population and according to cardiovascular risk factors. Eur Heart J 2014;35:3122-33.

69. Townsend RR, Roman MJ, Najjar SS, Cockcroft JR, Feig PU, Stockbridge NL. Central blood pressure measurements-an opportunity for efficacy and safety in drug development? J Am Soc Hypertens 2010;4:211-4.

70. Sola J, Proenca M, Chetelat O. Wearable PWV technologies to measure Blood Pressure: eliminating brachial cuffs. Conf Proc IEEE Eng Med Biol Soc 2013:4098-101.

71. Baschiera F, Chang W, Brunel P. Effects of aliskiren- and ramipril-based treatment on central aortic blood pressure in elderly with systolic hypertension: a substudy of AGELESS. Vasc Health Risk Manag 2014;10:389-97.

72. Whaley-Connell A, Purkayastha D, Yadao A, Sowers JR. Central pressure and biomarker responses to renin inhibition with 
hydrochlorothiazide and ramipril in obese hypertensives: the ATTAIN study. Cardiorenal Med 2011;1:53-66.

73. Townsend RR, Forker AD, Bhosekar V, Yadao A, Keefe DL. Comparison of aliskiren/hydrochlorothiazide combination therapy and amlodipine monotherapy in patients with stage 2 systolic hypertension and type 2 diabetes mellitus. J Clin Hypertens (Greenwich) 2011;13:889-97.

74. Ferdinand KC, Pool J, Weitzman R, Purkayastha D, Townsend R. Peripheral and central blood pressure responses of combination aliskiren/hydrochlorothiazide and amlodipine monotherapy in African American patients with stage 2 hypertension: the ATLAAST trial. J Clin Hypertens (Greenwich) 2011;13:366-75.

75. Black HR, Weinberger MH, Purkayastha D, Lee J, Sridharan K, Israel $\mathrm{M}$, et al. Comparative efficacy and safety of combination aliskiren/amlodipine and amlodipine monotherapy in African Americans with stage 2 hypertension. J Clin Hypertens (Greenwich) 2011;13:571-81.

76. Weber T, Auer J, O’Rourke MF, Kvas E, Lassnig E, Berent R, et al. Arterial stiffness, wave reflections, and the risk of coronary artery disease. Circulation 2004;109:184-9.

77. Roman MJ, Ganau A, Saba PS, Pini R, Pickering TG, Devereux RB. Impact of arterial stiffening on left ventricular structure. Hypertension 2000;36:489-94.

78. KDIGO clinical practice guideline for the management of blood pressure international society of nephrology. International Society of Nephrology; 2012. p. 2.

79. Aronow WS, Fleg JL, Pepine CJ, Artinian NT, Bakris G, Brown AS, et al. ACCF/AHA 2011 expert consensus document on hypertension in the elderly: a report of the American College of Cardiology Foundation Task Force on Clinical Expert Consensus documents developed in collaboration with the American Academy of Neurology, American Geriatrics Society, American Society for Preventive Cardiology, American Society of Hypertension, American Society of Nephrology, Association of Black Cardiologists, and European Society of Hypertension. $J$ Am Coll Cardiol 2011;57:2037-114.

80. K/DOQI clinical practice guidelines for cardiovascular disease in dialysis patients. Am J Kidney Dis 2005;45:S1-153.

81. Kim EJ, Song WH, Lee JU, Shin MS, Lee S, Kim BO, et al. Efficacy of losartan and carvedilol on central hemodynamics in hypertensives: a prospective, randomized, open, blinded end point, multicenter study. Hypertens Res 2014;37:50-6.

82. Shimizu M, Hoshide S, Ishikawa J, Yano Y, Eguchi K, Kario K. Correlation of central blood pressure to hypertensive target organ damages during antihypertensive treatment: the J-TOP study. Am J Hypertens 2015;28:980-6.

83. Kampus P, Serg M, Kals J, Zagura M, Muda P, Karu K, et al. Differential effects of nebivolol and metoprolol on central aortic pressure and left ventricular wall thickness. Hypertension 2011;57:1122-8.
84. Soanker R, Naidu MU, Raju SB, Prasad AK, Rao TR. Effect of beta-1-blocker, nebivolol, on central aortic pressure and arterial stiffness in patients with essential hypertension. Indian J Pharmacol 2012;44:407-11.

85. Studinger P, Tabak AG, Chen CH, Salvi P, Othmane TE, Torzsa P, et al. The effect of low-dose carvedilol, nebivolol, and metoprolol on central arterial pressure and its determinants: a randomized clinical trial. J Clin Hypertens (Greenwich) 2013;15:910-7.

86. Zhou WJ, Wang RY, Li Y, Chen DR, Chen EZ, Zhu DL, et al. A randomized controlled study on the effects of bisoprolol and atenolol on sympathetic nervous activity and central aortic pressure in patients with essential hypertension. PLoS One 2013;8:e72102.

87. Redon J, Pascual-Izuel JM, Rodilla E, Vicente A, Olivan J, Bonet J, et al. Effects of nebivolol and atenolol on central aortic pressure in hypertensive patients: a multicenter, randomized, double-blind study. Blood Press 2014;23:181-8.

88. Kanaoka T, Tamura K, Ohsawa M, Wakui H, Maeda A, Dejima T, et al. Effects of aliskiren-based therapy on ambulatory blood pressure profile, central hemodynamics, and arterial stiffness in nondiabetic mild to moderate hypertensive patients. J Clin Hypertens (Greenwich) 2012;14:522-9.

89. Williams B, Lacy PS, Baschiera F, Brunel P, Dusing R. Novel description of the 24-hour circadian rhythms of brachial versus central aortic blood pressure and the impact of blood pressure treatment in a randomized controlled clinical trial: the Ambulatory Central Aortic Pressure (AmCAP) Study. Hypertension 2013;61:1168-76.

90. Bonadei I, Vizzardi E, D’Aloia A, Sciatti E, Raddino R, Metra M. Role of aliskiren on arterial stiffness and endothelial function in patients with primary hypertension. J Clin Hypertens (Greenwich) 2014;16:202-6.

91. Lacy PS, Brunel P, Baschiera F, Botha J, Williams B. Effects of exercise on central aortic pressure before and after treatment with renin-angiotensin system blockade in patients with hypertension. J Renin Angiotensin Aldosterone Syst 2015;16: 1052-60.

92. Lacy PS, Brunel P, Bader G, Jones A, Baschiera F, Dusing R, et al. Effects of treatment withdrawal on brachial and central aortic pressure after direct renin inhibition or angiotensin receptor blockade. J Renin Angiotensin Aldosterone Syst 2015; 16:614-22.

93. Kwon BJ, Jang SW, Choi KY, Kim DB, Cho EJ, Ihm SH, et al. Comparison of the efficacy between hydrochlorothiazide and chlorthalidone on central aortic pressure when added on to candesartan in treatment-naive patients of hypertension. Hypertens Res 2013;36:79-84.

94. Izzo Jr JL, Rajpal M, Karan S, Srikakarlapudi S, Osmond PJ. Hemodynamic and central blood pressure differences between carvedilol and valsartan added to lisinopril at rest and during exercise stress. J Am Soc Hypertens 2012;6:117-23. 